\title{
A técnica da controvérsia controlada sob a perspectiva do enfoque CTS: uma contribuição para o ensino de biologia
}

Liliane Baldan Zani

Claudia Lougon Paiva

lan Drumond Duarte

Mirian do Amaral Jonis Silva

\section{Resumo}

O presente trabalho teve por objetivo observar aulas de biologia com enfoque CTS utilizando a técnica da controvérsia controlada, e verificar se os alunos obtiveram maior senso crítico a respeito do tema controverso proposto. Utilizou-se como método a pesquisa qualitativa e a observação in loco da técnica da controvérsia controlada em turmas de Ensino Médio de uma escola pública. A pesquisa de campo revelou que a maioria dos alunos alcançou uma percepção mais crítica no âmbito social, econômico e científico da temática após as atividades. As análises decorrentes dos resultados do trabalho apontam para a necessidade de abordagens didáticas inovadoras, que deem conta da complexidade do atual momento histórico, em que o desenvolvimento científico e tecnológico está cada vez mais presente na sociedade.

Palavras-chave: CTS; Controvérsia Controlada; Ensino de Biologia.

\section{Abstract}

The technique of controlled controversy in the perspective of approach STS: a contribution to the teaching of biology

The present study aimed to observe classes in biology with a focus STS using the technique of controlled controversy, to check if students had more critically about the controversial topic proposed. Was used a qualitative research method and in loco observation technique of controlled controversy in groups of high school at a public school. The field research revealed that most of the students reached a more critical perception of the issue, so they have a vision of social, economic and scientific activities after the topic. The analysis from the results of the study indicate to necessary for innovative didactical approaches, that account the complexity of the present historical moment in which the scientific and technological development is increasingly present in society.

Key words: STS; Controlled Controversy; Teaching Biology. 


\section{Introdução}

A necessidade do cidadão de conhecer os direitos e obrigações de cada um, de pensar por si próprio e ter uma visão crítica da sociedade onde vive e especialmente a disposição de transformar a realidade para melhor são alguns dos lemas do movimento CTS (Ciência, Tecnologia e Sociedade). Embora o movimento CTS não tenha tido sua origem no contexto escolar, as reflexões nesta área estão crescendo cada vez mais, por entender que é na escola que as mudanças começam a acontecer (PINHEIRO, 2005).

Essas mudanças devem ocorrer, pois a alfabetização não pode ser encarada como um jogo mecânico de juntar letras, mas deve proporcionar ao cidadão à capacidade da "leitura do mundo". Deste modo, para uma leitura crítica da realidade, torna-se, fundamental uma compreensão crítica sobre as interações entre Ciência, Tecnologia e a Sociedade, considerando que a dinâmica social contemporânea está fortemente marcada pela presença da Ciência e Tecnologia (AULER, 2006).

Pelo fato de o ensino tradicional não conseguir formar o cidadão em ciência e tecnologia com um pensamento mais politizado, surgiram vários trabalhos curriculares em CTS desenvolvidos em países industrializados como na Europa, nos Estados Unidos, no Canadá e na Austrália, em que havia necessidades quanto à educação científica e tecnológica (SANTOS \& MORTIMER, 2002). Tinha-se uma visão deformada acerca da ciência, que era vista como uma atividade autônoma, neutra e isolada de outros contextos, bem como a atribuição de algumas consequências de seu mau uso em determinadas tecnologias. O Movimento CTS surge num contexto em que questões acerca de tais consequências ganham força e passa a se exigir maior atenção às atitudes com relação à ciência e tecnologia (ROEHRIG \& CAMARGO, 2012).

No Brasil na década de 1970 os currículos de ciências começaram a incorporar uma visão de ciência como produto do contexto econômico, político e social. Já na década 1980, a renovação do ensino de ciências passou a se orientar pelo objetivo de analisar as implicações sociais do desenvolvimento científico e tecnológico. E em 1990, aconteceu a "Conferência Internacional de Ensino de Ciências para o Século XXI: ACT - Alfabetização em Ciência e Tecnologia", em que o foco central foi à educação científica dos cidadãos (SANTOS, 1999).

Atualmente a reforma curricular do ensino médio incorpora elementos dos currículos com ênfase em CTS (SANTOS \& MORTIMER, 2002), em que o objetivo central é desenvolver a alfabetização científica e tecnológica voltada para a cidadania, no sentido de permitir que o aluno possa compreender e tomar decisões responsáveis sobre questões de ciência e tecnologia na sociedade e atuar na solução de tais questões (AIKENHEAD, 1994).

Segundo Auler (1998), o objetivo do enfoque educacional CTS para o ensino de ciências é: promover o interesse dos estudantes em relacionar a ciência com as aplicações tecnológicas e os fenômenos da vida cotidiana, e abordar o estudo daqueles fatos e aplicações científicas que 
tenham uma maior relevância social; abordar as implicações sociais e éticas relacionadas ao uso da tecnologia e adquirir uma compreensão da natureza, da ciência e do trabalho científico.

A concepção CTS para o ensino de ciências aponta para um ensino que ultrapasse a meta de uma aprendizagem de conceitos e de teorias relacionadas com conteúdos canônicos, em direção a um ensino que tenha uma validade cultural, para além da validade científica. Tem como alvo, ensinar a cada cidadão comum o essencial para chegar a sê-lo de fato, aproveitando os contributos de uma educação científica e tecnológica (SANTOS \& MORTIMER, 2002).

Os Parâmetros Curriculares Nacionais (PCN) difundem a ideia de levar para sala de aula o debate sobre as relações existentes entre ciência, tecnologia e sociedade - tanto no Ensino Fundamental quanto no Ensino Médio - como forma de Educação Tecnológica, a qual não seria voltada para confecção de artefatos, mas para a compreensão da origem e do uso que se faz desses artefatos na sociedade atual (PINHEIRO, 2005). Para isso, a Educação Tecnológica deve levar os alunos a compreender a dimensão social da ciência e tecnologia, tanto do ponto de vista dos seus antecedentes sociais quanto de suas consequências sociais e ambientais (PALACIOS et al., 1996).

\section{Metodologia}

O campo da pesquisa foi a Escola Estadual de Ensino Médio "Professor Fernando Duarte Rabelo" localizada na cidade de Vitória - ES, escolhida de acordo com a disponibilidade e a receptividade da equipe escolar frente à ideia de que uma coleta de dados fosse ali desenvolvida. A pesquisa foi realizada com turmas regulares dos segundos e terceiros anos do Ensino Médio, composta por cerca de 30 alunos cada. Essas turmas foram escolhidas pela professora de biologia de acordo com o planejamento curricular. A faixa etária desses alunos está entre 15 a 17 anos, em sua maior parte, são moradores de uma comunidade da cidade de Vitória.

A professora foi escolhida para o estudo por ter participado de um curso de capacitação oferecido pela SEDU (Secretaria de Educação do Espírito Santo) com enfoque CTS onde se utilizou a técnica da controvérsia controlada. A carga horária destinada à disciplina de Biologia nas Escolas da Rede Estadual de Ensino Médio compreende duas aulas semanais com duração de uma hora cada aula.

A fim de atender o objetivo da pesquisa, que por sua vez tratou-se de uma pesquisa qualitativa, a estratégia geral da coleta de dados consistiu no acompanhamento, de todas as aulas de biologia ministradas às turmas de segundos e terceiros anos do ensino médio. Ao todo foram observadas 30 aulas distribuídas em quatro etapas: diagnóstico inicial, pesquisa, debate simulado e diagnóstico final. 


\section{Resultados e Discussão}

As aulas de Biologia, para as turmas escolhidas, foram observadas de maneira sistemática durante um bimestre (julho e agosto de 2010), totalizando 36 aulas de 60 minutos cada. A professora é considerada uma 'boa profissional' tanto pelos alunos quanto pela escola e segundo Pereira e Garcia (1996) o conceito de 'bom' possui diversos vieses, ligados da psicologia à sociologia, mas para o senso comum, cotidiano, no qual se apoiam os valores dos alunos, o 'bom' corresponde ao correto, ao eficiente, à satisfação, ao apropriado. Assim, a qualidade de 'ser bom', implica numa série de fatores que estão ligados à competência, à pro eficiência, à habilidade, etc. Aquele que é considerado 'bom', relaciona-se à sua capacidade docente, com natureza e função educativa.

Considerando esse bom desempenho da professora frente aos alunos e a escola, esta foi convidada a participar de um curso de formação continuada promovido pela SEDU destinado aos professores da rede estadual de ensino que abordava o enfoque CTS utilizando a técnica da controvérsia controlada. Neste os professores compreenderam as questões norteadoras do enfoque CTS e uma das técnicas para sua aplicação em sala de aula. O curso foi destinado aos professores das áreas de ciências (Física, Química, Matemática e Biologia).

Segundo Bispo et al. 2012, esses cursos de formação de professores estão cada vez mais comprometidos com a necessidade de utilizar recursos originais e criativos para que os novos educadores possam adquirir um perfil profissional voltado aos desafios mais urgentes de uma sociedade multimídia, globalizada, mas também, e principalmente, mais humana . Então, após o curso a professora passou a utilizar em suas aulas o enfoque CTS de maneira a mostrar aos alunos a influência da ciência e da tecnologia na sociedade.

Pode-se observar que a professora possui um bom relacionamento com seus alunos o que deixa a aula mais descontraída e leva a uma melhor aprendizagem do conteúdo. Para que o processo ensino-aprendizagem ocorra, a professora busca meios alternativos para complementar a aula, como por exemplo, aulas de campo e aulas experimentais. Para tanto é necessário à capacitação dos professores com o objetivo de atualizar suas condutas em sala de aula.

É importante enfatizar que o ato de ensinar do professor não se pode reduzir somente aos aspectos observáveis na sala de aula, deve-se levar em consideração também outros aspectos que têm lugar importante no processo ensino-aprendizagem como: conversa com os alunos fora da sala de aula, preparo das aulas, convivência com os colegas, entre outros.

\section{Divisão dos grupos}

Ao se iniciar as observações, a professora mostrou-se disposta a contribuir com a pesquisa e disponibilizou todo o material que seria utilizado nas aulas com enfoque CTS. A escolha 
do tema "Proibição do Fumo: decisão pessoal ou social?" (CHRISPINO, 2005) para direcionar a atividade foi feita pela professora uma vez que no período da pesquisa a Lei que proíbe o fumo em locais públicos fechados entrou em vigor. Porém essa escolha foi desvinculada do conteúdo abordado nas turmas pesquisadas, pois nestas estava sendo trabalhado o conteúdo de genética, tornando o trabalho com enfoque CTS algo isolado daquilo que estava sendo estudado em sala de aula.

Walks, Medina e Sanmartín (1990), classificam as experiências voltadas para o enfoque CTS na educação em três modalidades: introdução de CTS nos conteúdos das disciplinas de ciências (enxerto CTS); a ciência vista por meio de CTS; e CTS puro. Segundo Palacios et al. (1996), essas categorias podem ser resumidas das seguintes formas:

- Enxerto CTS: introdução de temas CTS nas disciplinas de ciências, abrindo discussões e questionamentos do que seja ciência e tecnologia;

- Ciência e tecnologia por meio de CTS: estrutura-se o conteúdo científico por meio do CTS. Essa estruturação pode acontecer numa só disciplina ou por meio de trabalhos multidisciplinares e interdisciplinares;

- CTS puro: ensina-se ciência, tecnologia e sociedade por intermédio do CTS, no qual o conteúdo científico tem papel subordinado.

Nas três modalidades, o professor é o grande articulador para garantir a mobilização dos saberes, o desenvolvimento do processo e a realização de projetos, nos quais os alunos estabelecem conexões entre o conhecimento adquirido e o pretendido com a finalidade de resolver situações-problema, em consonância com suas condições intelectuais, emocionais e contextuais.

Com base na classificação sugerida por Walks, Medina e Sanmartín (1990), foi possível observar que a modalidade utilizada pela professora foi o enxerto CTS uma vez que o tema sugerido não possuía relação com o conteúdo abordado em sala. A professora utilizou a técnica da controvérsia controlada para inserir o enfoque CTS na sala de aula. Para a realização deste procedimento, em primeiro lugar, ela aplicou um questionário inicial que consistia de 10 questões dissertativas. Essas questões estavam relacionadas aos conhecimentos prévios dos alunos sobre o tema a ser trabalhado e também aos conhecimentos adquiridos após a aplicação do método. Foi necessária uma aula de 60 minutos para a conclusão do questionário.

O questionário estava estruturado em duas colunas sendo que a da esquerda era destinada ao diagnóstico inicial e a outra coluna ao diagnóstico final. O diagnóstico inicial foi baseado nos conhecimentos prévios dos alunos e na conversa inicial da professora frente ao tema proposto. 
Alves (2001) considera que o professor precisa contemplar a prática vivida pelos alunos como ponto inicial do planejamento e da implementação do currículo e do ensino. Para isso, é preciso que os alunos tenham a oportunidade de expressar suas ideias, portanto, é preciso gerar um ambiente em que seja possível que os alunos se abram, façam perguntas e comentem o processo que seguem, através de situação de diálogo e participação, como meio para exploração dos conhecimentos prévios. Dessa forma, as atividades foram desenvolvidas, de forma geral, por meio de um tema controverso, que por sua vez contribui para a inserção de discussões sóciocientíficas, relacionadas à ética e aos problemas contemporâneos (SANTOS e AULER, 2011).

Esse diagnóstico foi feito a partir de uma conversa inicial da professora com a turma em que foi exposto o tema "Proibição do Fumo: decisão pessoal ou social?" e a importância do enfoque CTS para as provas contextualizadas, por exemplo, as provas do Exame Nacional do Ensino Médio (ENEM) que ocorreriam posteriormente para os alunos. Os alunos apresentaram uma reação positiva a essa primeira parte. Logo após a professora dividiu a turma em cinco grandes grupos de atores (CHRISPINO, 2005):

- Grupo 01: Grupo de Trabalho para a Organização da Conferência sobre a Proibição do Uso do Fumo;

- Grupo02: Associação das Indústrias de Tabaco;

- Grupo 03: ONG Pesquisadores e Profissionais de Saúde Unidos contra o Fumo;

- Grupo 04: ONG Em defesa da Vida;

- Grupo 05: ONG Associação em defesa dos fumantes fumarem.

Na maioria das turmas foi observada uma grande dificuldade em dividir os alunos em grupos devido às afinidades existentes, mas essa dificuldade foi superada com a desenvoltura da professora diante da situação. Com os grupos divididos, os alunos foram encaminhados ao laboratório de informática a fim de realizarem uma busca de informações para sustentar seus argumentos no dia do debate.

A professora orientou cada grupo de trabalho direcionando as pesquisas. Para essa atividade foram utilizadas duas aulas de 60 minutos. Nesta atividade os alunos envolveram-se de forma responsável e concluíram a pesquisa mesmo quando a professora se ausentava do laboratório, o que demonstra um grande interesse pelo processo.

\section{O Debate Simulado}

O debate é uma estratégia de ensino que possibilita a exposição de pontos de vista diferentes sobre uma mesma questão e que pode contribuir para desenvolver o poder de argumentação dos alunos. Por se tratar de uma atividade em que os alunos assumem papéis 
distintos e posicionamentos contrários acerca de determinada questão, sem que, necessariamente, concordem com o que estão defendendo, essa discussão denomina-se debate simulado.

O debate ocorreu de forma peculiar em cada sala. Em algumas turmas o grupo de Trabalho para a Organização da Conferência sobre a Proibição do Uso do Fumo iniciou o debate com uma apresentação em forma de slides mostrando as duas faces do fumo. Isso norteou o debate e serviu como base para os outros grupos exporem seus argumentos.

Outras turmas iniciaram o debate sem uma apresentação do assunto e já partiram direto para as discussões, inserindo perguntas para incitar os demais grupos. Já em outras o grupo não conseguiu mediar o debate sendo necessária a intervenção da professora. Os grupos de trabalho apresentaram seus argumentos e deram seguimento ao debate. Alguns mostraram vídeos, fotos e textos para complementar suas falas. Outros não foram bem claros em alguns pontos ou não se expressaram, entretanto outros se destacaram e obtiveram mais sucesso em suas argumentações.

Os Grupos Associação das Indústrias de Tabaco e ONG Associação em defesa dos fumantes fumarem, que no inicio pensaram ser quase impossível defender esses pontos, apresentaram bons argumentos. É possível citar alguns destes:

"Os fumantes são informados nas embalagens os malefícios do cigarro, e continuam fumando mesmo sabendo os riscos que correm (...). As indústrias de cigarro geram empregos e impostos que por sua vez podem ser revertidos em benefícios para a população". Grupo 02 Associação das Indústrias de Tabaco.

"Não é apenas o toco do cigarro a causa das queimadas, outros fatores são responsáveis também, como por exemplo, cacos de vidro no sol." Grupo 05 - ONG Associação em defesa dos fumantes fumarem.

A professora incentivou a participação de todos nas discussões ocorrendo muitas vezes até certo tumulto em que todos queriam falar ao mesmo tempo. Em geral os debates foram bastante produtivos, pois os alunos se interessaram pelas discussões científicas atuais e aprenderam como participar das mesmas e a exercer a cidadania, sendo estas a finalidade principal dessa atividade (VIEIRA \& BAZZO, 2007). Isto se deve ao fato da educação em ciências proporcionar a todos os estudantes a oportunidade de desenvolver capacidades que neles despertem a inquietação diante do desconhecido, buscando explicações lógicas e razoáveis, levando os alunos a desenvolverem posturas críticas, realizar julgamentos e tomar decisões fundamentadas em critérios objetivos, baseados em conhecimentos compartilhados por uma comunidade escolarizada (BIZZO, 1998). 
Para a realização desta etapa muitos imprevistos ocorreram, uma vez que os grupos utilizaram de alguns recursos audiovisuais para complementação de suas apresentações. Muitas vezes houve demora na montagem destes equipamentos e até mesmo dificuldade na organização da sala nas quais os alunos foram dispostos em círculo.

\section{Diagnóstico inicial $x$ diagnóstico final}

Dos questionários analisados foi possível observar que alguns alunos obtiveram mudanças em sua opinião inicial. Notaram-se mudanças de posicionamento em relação às temáticas discutidas e em outros casos houve apenas uma complementação dos conhecimentos já existentes. A maioria dos alunos possuía conhecimentos pouco elaborados e muito influenciados pelo senso comum. Pra melhor categorização das respostas dos alunos foi criado um quadro que apresenta uma escala de níveis de apropriação de conhecimento sobre a questão do fumo (Quadro 01).

Quadro 01. Representação de uma escala de níveis de apropriação de conhecimento sobre a questão do fumo.

\begin{tabular}{|c|l|}
\hline Níveis & \multicolumn{1}{|c|}{ Especificação } \\
\hline Nível 1 & $\begin{array}{l}\text { Visão restrita - utiliza informações de senso comum e sem referência ao } \\
\text { conhecimento científico nem ao impacto social. }\end{array}$ \\
\hline Nível 2 & $\begin{array}{l}\text { Visão unilateral - baseada ora em informações científicas difusas sem } \\
\text { fundamentação, ora no contexto social sem uma reflexão crítica. Não estabelece } \\
\text { uma relação clara entre as dimensões científica e social. }\end{array}$ \\
\hline Nível 3 & $\begin{array}{l}\text { Visão multidimensional - referenciada no conhecimento científico e no contexto } \\
\text { social - sua opinião transita entre a questão cientifica e social, porém sem uma } \\
\text { visão mais crítica acerca do tabagismo. }\end{array}$ \\
\hline Nível 4 & $\begin{array}{l}\text { Visão sistêmica do assunto-reconhece diferentes pontos de vista sobre o uso do } \\
\text { fumo, embasa suas opiniões em conhecimentos científicos e possui uma } \\
\text { percepção crítico-social do tabagismo. }\end{array}$ \\
\hline
\end{tabular}

A análise dos questionários de diagnóstico inicial e diagnóstico final sugere uma evolução dos grupos em relação à conscientização e à percepção do caráter social e político do tabagismo, a partir de atividades orientadas pelo enfoque CTS. As respostas de alguns dos participantes ao diagnóstico inicial e diagnóstico final foram transcritas no quadro 02 e correspondem aos fragmentos retirados dos questionários que continham a seguinte pergunta: "Escreva quais as consequências do uso do fumo para a saúde do não fumante (fumante passivo)".

Para essa questão foi possível observar que o aluno E.F.A. passou por um processo de mudança em seus conceitos prévios apoiados no senso comum e que a questão antes da atividade era pouco esclarecida pra ele, notou-se que este aluno passa do nível 01 para o nível 02 na escala de apropriação de conhecimento sobre a questão do fumo. Já os alunos C.M. e C.C.N. 
tiveram um acréscimo de informação em suas respostas, não sendo observada uma mudança de nível, eles permanecem, portanto no nível 02.

Esse acréscimo de informação foi devido à pesquisa feita antes do debate que possibilitou um maior embasamento nas respostas dadas. Porém, algumas vieram acompanhadas de uma percepção social e uma fundamentação científica ao citar algumas doenças comuns, isto pode ser observado na resposta do aluno C.G.M. neste caso é possível afirmar uma passagem do nível 01 para o nível 03.

Quadro 02. Evolução da percepção crítica pelos participantes com relação à questão: "Escreva quais as consequências do uso do fumo para a saúde do não fumante (fumante passivo)."

\begin{tabular}{|c|c|}
\hline Diagnóstico inicial & Diagnóstico final \\
\hline $\begin{array}{l}\text { "São boas às consequências, pois não vão } \\
\text { ingerir uma coisa que pode matá-los e evitam } \\
\text { muitas doenças que podem levá-los à morte." }\end{array}$ & $\begin{array}{l}\text { "Muitas das vezes os fumantes passivos } \\
\text { acabam sendo vítimas de doenças do fumo, } \\
\text { pois mesmo eles não fumando, quando um } \\
\text { fumante fuma perto deles é como se eles } \\
\text { estivessem fumando também." }\end{array}$ \\
\hline $\begin{array}{l}\text { "As mesmas dos fumantes ativos, até mais, pois } \\
\text { sofrem as consequências e não fumam." } \\
\text { C.C.N. }\end{array}$ & $\begin{array}{l}\text { "A fumaça que saí do toco do fumante sai } 03 \\
\text { vezes mais perigosa do que o que passa pelo } \\
\text { filtro." } \\
\text { C.C.N. }\end{array}$ \\
\hline $\begin{array}{l}\text { "Ele é um fumante passivo e dependendo da } \\
\text { situação ele também pode ter doença de um } \\
\text { fumante." } \\
\text { C.M. }\end{array}$ & $\begin{array}{l}\text { "Dependendo do grau da absorção, o fumante } \\
\text { passivo pode fumar o mesmo que dois cigarros } \\
\text { por dia." }\end{array}$ \\
\hline $\begin{array}{l}\text { "Bom tem as mesmas consequências do cara } \\
\text { que fuma." }\end{array}$ & $\begin{array}{l}\text { "Além do desrespeito para a saúde do não } \\
\text { fumante tem as mesmas consequências dos } \\
\text { fumantes, câncer, perda de peso, é claro menos } \\
\text { agressivos." } \\
\text { C.G.M. }\end{array}$ \\
\hline
\end{tabular}

Ao analisar a pergunta "Se eu fumar os cigarros de baixo teor não haverá problemas. Esta correta esta afirmação?" (Quadro 03), pode-se a verificar que alguns alunos não apresentaram mudanças em suas concepções uma vez que já possuíam a informação pertinente ao assunto e a atividade não foi suficiente para acrescentar informações novas, como o aluno M.N. que se encontra no nível 01, por exemplo.

Outros alunos, porém, apresentaram a mesma resposta, mas em parte acrescentaram mais informações de cunho social, como por exemplo, a resposta do aluno C.G.M. Esse caso pode ser explicado por Johnson (2004), na qual afirma que a satisfação do conflito - causado pela diferença de percepção/opinião - acarreta uma racionalidade e um novo aprendizado, gerando a reconceitualização sobre o tema em debate. Essa reconceitualização não é, obrigatoriamente, uma modificação da posição anterior. Neste caso pode-se dizer que houve permanência no nível 02 da escala de apropriação de conhecimento sobre a questão do fumo.

Um caso que chamou atenção foi o do aluno F.N., que mostrou em suas respostas, tanto no diagnóstico inicial quanto no final, uma definição errônea acerca dos cigarros de baixo teor. 
Mesmo as atividades que levaram eles a buscarem informações e debaterem sobre elas, não foram suficientes para causar uma mudança do nível 01 .

Quadro 03. Evolução da percepção crítica pelos participantes com relação à pergunta: "Se eu fumar os cigarros de baixo teor não haverá problemas. Esta correta esta afirmação?"

\begin{tabular}{|c|c|}
\hline Diagnóstico inicial & Diagnóstico final \\
\hline $\begin{array}{l}\text { "Não, desde que você fume terá problemas, } \\
\text { não importa qual seja o cigarro." } \\
\text { M.N. }\end{array}$ & $\begin{array}{l}\text { "A afirmação continua incorreta, qualquer } \\
\text { cigarro contém as mesmas substâncias, mesmo } \\
\text { que seja com baixos teores." }\end{array}$ \\
\hline $\begin{array}{l}\text { "Não, tem as mesmas consequências dos } \\
\text { outros cigarros." }\end{array}$ & $\begin{array}{l}\text { "Minha opinião é a mesma, traz as mesmas } \\
\text { consequências, porém é pior, pois causa maior } \\
\text { curiosidade em jovens e por alguns ter cheiro e } \\
\text { gosto acabam viciando mais rápido." } \\
\text { C.G.M. }\end{array}$ \\
\hline $\begin{array}{l}\text { "Eu acho que não, porque aí não vai ter muita } \\
\text { química." }\end{array}$ & $\begin{array}{l}\text { "Não, porque o cigarro LA não vai fazer mal } \\
\text { porque contém menos química que o normal." }\end{array}$ \\
\hline F.N. & F.N. \\
\hline
\end{tabular}

Na questão "Comente a expressão eu fumo porque quero paro quando quiser" (Quadro 04) houve um caso em específico em que o aluno G.S.C., mesmo pertencendo ao grupo que era contra o fumo, continua concordando com a expressão. Isso pode ser explicado segundo Johnson (2004), na qual afirma que o debate não visa à abdicação de posições, mas a oportunidade de apresentar suas ideias e de ouvir a argumentação do outro que pensa/sente diferentemente. 0 aluno então se encontra no nível 03 na escala de apropriação de conhecimento sobre a questão do fumo.

Quadro 04. Evolução da percepção crítica pelos participantes com relação à questão "Comente a expressão eu fumo porque quero paro quando quiser".

\begin{tabular}{|c|c|}
\hline Diagnóstico inicial & Diagnóstico final \\
\hline $\begin{array}{l}\text { "Todos nós somos donos de nossas vontades e } \\
\text { de nossas escolhas. Então as pessoas decidem } \\
\text { quando começam e quando param. Muitos } \\
\text { começam e não conseguem parar." } \\
\text { G.S.C. }\end{array}$ & $\begin{array}{l}\text { "Apesar de meu grupo e eu estarmos a favor da } \\
\text { lei contra o fumo, eu continuo com o mesmo } \\
\text { pensamento e opinião. Se nós sabemos que o } \\
\text { fumo é prejudicial à saúde e mesmo assim } \\
\text { muitos fumam é porque optaram por isso. O } \\
\text { difícil é sair dessa opção de vida." }\end{array}$ \\
\hline
\end{tabular}

No caso do aluno C.G.M. pode-se observar que houve uma mudança em sua resposta (Quadro 05) no diagnóstico final diante da questão "Qual o impacto da proibição total de plantio e comercialização do fumo?". O aluno adquiriu uma visão política e econômica o que não era possível notar em sua resposta no diagnóstico inicial. Ele passou do nível 02 para o nível 04 na escala de apropriação de conhecimento sobre a questão do fumo. 
Quadro 05. Evolução da percepção crítica pelos participantes com relação à pergunta "Qual o impacto da proibição total de plantio e comercialização do fumo?".

\begin{tabular}{|r|lr|}
\hline \multicolumn{2}{|c|}{ Diagnóstico inicial } & \multicolumn{2}{|c|}{ Diagnóstico final } \\
\hline $\begin{array}{l}\text { "Bom, causaria revolta nos fumantes. Não acho "Teria uma queda na economia além do } \\
\text { certo, a pessoa pode enlouquecer querendo } \\
\text { aquilo e não tendo." }\end{array}$ & $\begin{array}{l}\text { desemprego que causaria nas indústrias na } \\
\text { agricultura e no comércio." } \\
\text { C.G.M. }\end{array}$ & C.G.M. \\
\hline
\end{tabular}

No que diz respeito ainda à alteração de resposta podemos exemplificar com a pergunta “A propaganda tem alguma função na opção do jovem fumar ou não?". Nesta notou-se que foi possível através da técnica da controvérsia controlada pautada no do enfoque CTS promover uma maior percepção crítica acerca do tema. Todos os alunos destacados no quadro 06 apresentaram uma evolução em suas respostas no diagnóstico final e demonstraram que foi possível "aprender" através da técnica. Ambos os alunos passaram do nível 01 pra o nível 02 em que suas respostas apresentaram uma tendência ou para o lado socioeconômico ou para o lado científico.

Quadro 06. Evolução da percepção crítica pelos participantes com relação à pergunta "A propaganda tem alguma função na opção do jovem fumar ou não?".

\begin{tabular}{|c|c|}
\hline Diagnóstico inicial & Diagnóstico final \\
\hline $\begin{array}{l}\text { “Não, porque eles não fazem propaganda de } \\
\text { craque, maconha, cocaína e olha a quantidade } \\
\text { de jovens que usam." } \\
\text { C.G.M. }\end{array}$ & $\begin{array}{l}\text { "Sim, a televisão influência a curiosidade das } \\
\text { pessoas, principalmente dos jovens que são os } \\
\text { mais influenciados." } \\
\text { C.G.M. }\end{array}$ \\
\hline $\begin{array}{l}\text { "Não tem, o jovem começa a fumar, pois pensa } \\
\text { que assim as pessoas o verão como um adulto } \\
\text { responsável." } \\
\text { L.S.R. }\end{array}$ & $\begin{array}{l}\text { "Sim, pois o jovem usa tudo que está na mídia." } \\
\text { L.S.R. }\end{array}$ \\
\hline $\begin{array}{l}\text { "Creio que não, pois na própria embalagem há } \\
\text { os riscos do consumo do cigarro." } \\
\text { J.K.I.S. }\end{array}$ & $\begin{array}{l}\text { "Sim, ela pode auxiliá-lo e incentivá-lo negativa } \\
\text { ou positivamente." } \\
\text { J.K.I.S }\end{array}$ \\
\hline $\begin{array}{l}\text { "Não, os jovens começam a fumar por opção } \\
\text { própria." } \\
\text { J.S.V. }\end{array}$ & $\begin{array}{l}\text { "Sim, pois ela quer ter seu lucro como as } \\
\text { indústrias." } \\
\text { J.S.V. }\end{array}$ \\
\hline
\end{tabular}

\section{Considerações Finais}

É importante ressaltar que o presente trabalho, frente à aplicação da técnica da controvérsia controlada orientada pelo enfoque CTS, cumpriu com seus objetivos no que se refere à observação dos alunos em cada etapa do processo, na análise dos questionários iniciais e finais. Ao analisar a atividade proposta foi possível verificar que ainda faltam bases teóricas na orientação dos professores frente ao que seja uma aula na perspectiva do enfoque CTS, pois 
muitas vezes o enfoque CTS é associado único e exclusivamente a técnica da controvérsia controlada.

Essa técnica é apenas uma das possibilidades de trazer para dentro da sala de aula assuntos polêmicos que possam ser tratados sob uma abordagem CTS. Com isso percebe-se a necessidade de novas abordagens didáticas que deem conta da complexidade do atual momento histórico, em que o desenvolvimento científico e tecnológico está cada vez mais presente na sociedade. Para isso tornam-se fundamentais cursos de capacitação de profissionais da educação sob a perspectiva CTS, sendo importante mostrar a eles a diversidade de técnicas para a abordagem CTS. Para tanto é imprescindível esclarecer a esses professores que CTS não é uma técnica ou uma metodologia e sim uma percepção pedagógica

\section{Agradecimentos}

Agradecemos a Escola Professor Fernando Duarte Rabelo, a professora Ivy e aos alunos dos segundos e terceiros anos do ensino médio que gentilmente aceitaram participar da nossa pesquisa. 


\section{Referências}

Aikenhead, G. (Eds.). STS education: international perspectives on reform. New York: Teachers College Press, p. 47-59. 1994.

Alves, N. F (org.).Formação de professores: pensar e fazer. Questões de nossa época. 6a Ed. São Paulo: Cortez, 103p. 2001.

Auler, D. Movimento ciência-tecnologia-sociedade (CTS): modalidades, problemas e perspectivas em sua implementação no ensino de física. In: VI Atas do Encontro Nacional de Pesquisa em Ensino de Física.Florianópolis: SBF. 1998.

Auler, D.; Delizoicov, D. Educação CTS: Articulação entre pressupostos do Educador Paulo Freire e referenciais ligados ao Movimento CTS. In: Las Relaciones CTS en la Educación Científica. Málaga, Espanha, 2006.

Bispo, M. L. P.; Mathias, G. N.; Amaral, C. L. C. Desenvolvimento de projetos de trabalho com enfoque CTS Entre Alunos De Licenciatura Em Biologia. Anais do II Seminário Hispano Brasileiro CTS. p. 457-466, São Paulo, 2012.

Bizzo, N. Ciências: fácil ou difícil. Ed. Ática, São Paulo, SP, 1998.

Bogdan, R.; Biklen, S. Investigação Qualitativa em Educação. Uma Introdução à Teoria e aos Métodos. ColeçãoCiências da Educação. Porto Editora.335p. 1994.

Johnson, A. L. Industrial Research Institute's R\&D Trends Forecast for Research Technology Management; Jan/Feb 2004; 47, 1; pg. 17.2004.

Palacios, F. A.; Otero, G. F.; Gárcia, T. R. Ciencia, Tecnología y Sociedad. Madrid: Ediciones Del Laberinto, 1996.

Pinheiro, N. A. M. Educação Crítico-Reflexiva para um Ensino Médio Científico-Tecnológico: a contribuição do enfoque CTS para o ensino-aprendizagem do conhecimento matemático. Tese (Doutorado em Educação Cientifica e Tecnológica). Universidade Federal de Santa Catarina, Florianópolis, 2005.

Roehrig, S. A. G. e Camargo, S. A educação com enfoque CTS no quadro das tendências de pesquisa em Ensino de Ciências: Algumas reflexões sobre o contexto Brasileiro atual. III Simpósio Nacional de Ensino de Ciência e Tecnologia. Ponta Grossa, 2012.

Santos, M. E. Encruzilhadas de mudança no limiar do século XXI: co-construção do saber científico e da cidadania via ensino CTS de ciências. In: Atas do II Encontro Nacional de Pesquisa em Educação em Ciências. Valinhos, SP. 1999. 
Santos, W. L. P.; Mortimer, E. F. Uma análise de pressupostos teóricos da abordagem C-T-S (Ciência - Tecnologia -Sociedade) no contexto da educação brasileira. Revista Ensaio - Pesquisa em Educação em Ciência, vol. 2, n. 2, dezembro, 2002.

Santos, W. L. P. Significados da educação científica com enfoque CTS. In: Santos, W. L. P. e Auler, D. CTS e educação científica: desafios, tendências e resultados de pesquisa. Brasília: Editora Universidade de Brasília, p. 21-47. 2011.

Pereira, F. M; Garcia, M. A. D. Educação Física no segundo grau: as práticas pedagógicas de seus bons professores. Relatório (Iniciação Cientifica) Universidade Federal de Pelotas, Pelotas, 1996.

Vieira, K. R. C. F.; Bazzo, W. A. Discussões acerca do aquecimento global: uma proposta CTS para abordar esse tema controverso em sala de aula. Ciência \& Ensino, 01 (n.esp.), 2007.

Walks, L. Educación en ciencia, tecnología y sociedad: orígenes, desarrollos internacionales y desafíos intelectuales. In: MEDINA, M.; SANMARTIN, J. (Orgs.). Ciencia, tecnología y sociedad, estudios interdisciplinares en la universidad, en la educación y en la gestión pública. Barcelona: Anthropos, p. 42-75. 1990.

Liliane Baldan Zani. Licenciada Plena e Bacharel em Ciências Biológicas pela Universidade Federal do Espírito Santo. Mestranda do Programa de Pós-Graduação em Biologia Vegetal da Universidade Federal do Espírito Santo. Contato: lilianebzani@gmail.com

Claudia Lougon Paiva. Licenciada Plena e Bacharel em Ciências Biológicas pela Universidade Federal do Espírito Santo. Mestre em Genética e Melhoramento de plantas pela Universidade Estadual do Norte Fluminense. Doutoranda em Genética e Melhoramento de plantas da Universidade Estadual do Norte Fluminense.

Ian Drumond Duarte. Licenciado Pleno e Bacharel em Ciências Biológicas pela Universidade Federal do Espírito Santo. Mestrando do Programa de Pós-Graduação em Biologia Vegetal da Universidade Federal do Espírito Santo.

Mirian do Amaral Jonis Silva. Licenciada em Ciências Biológicas pela Universidade Federal do Rio de Janeiro. Mestre e Doutora em Educação pela Pontifícia Universidade Católica do Rio de Janeiro. Professora Adjunta do Centro de Educação e do Programa de Pós-Graduação em Ensino de Física - PPGEnFis da Universidade Federal do Espírito Santo. 